\title{
REGIONAL DEVELOPMENT PROGRAMS: A CRITICAL VIEW*
}

\author{
Ronald Moomaw
}

University of Virginia

In discussing Mr. Rothblatt's paper I will emphasize two general points concerning regional development policy. First, attempts to change population or per capita income distributions over space through planning or tax/ subsidy schemes will be very costly and may fail. Secondly, most politically feasible regional development programs imposed by the Federal Government will allow any relatively poor county or district to prepare a "wish list" or to make a "reasonable" request for Federal development funds. Consequently, many areas will be aligible for and will receive these funds; the only constraint on the regional development expenditures being the porportion of the Federal budget devoted to these programs. Finally, I would like to question Mr. Rothblatt's evaluation of the benefits of planning in Appalachia, and make a brief suggestion for a new direction for regional planning in the United States.

To illustrate the difficulties involved in regional development programs I will develop a comparison between two rural areas in Virginia, the Northern Shenandoah Valley and Southwestern Virginia. ${ }^{1}$ The two areas are similar in that they are under the same state government and are generally comparable in terms of the characteristics of their populations and their economies. One significant difference is that the latter area receives regional development funds from the Federal Government; the former does not.

TABLE I

Northern Shenandoah Valley Southwestern Virginia

\begin{tabular}{|c|c|}
\hline \multicolumn{2}{|l|}{ Average per capita income } \\
\hline $1939 \$ 300$ & $\$ 240$ \\
\hline 2000 & 1250 \\
\hline \multicolumn{2}{|l|}{ Percentage Population Growth } \\
\hline $1950-1960 \quad 8.5 \%$ & $-9.9 \%$ \\
\hline \multicolumn{2}{|c|}{ Expenditure per student on education } \\
\hline$\$ 350$ & $\$ 300$ \\
\hline
\end{tabular}

Source: Thomas Jefferson Center for Political Economy, University of Virginia, Statistical Abstract of Virginia

As shown in Table I, the Northern Valley is a relatively prosperous area with an average per capita income in 1965 of approximately $\$ 2000$ compared with an average per capita income of approximately $\$ 1250$ in Southwestern Virginia. Interestingly enough, the per capita incomes in both areas have increased at about the same rate since 1939. The relative poverty in the latter area is a reflection of a longstanding economic disadvantage rather than recent economic disturbances which might have inhibited the rate of growth of per capita income. The most obvious disadvantage is its location. The central part of the Northern Valley lies only one hundred miles from Washington, D. C., the southern fringe of the large Northeastern market. 
In comparison, the central part of the Southwestern area lies about three hundred fifty miles from Washington.

Another factor which has disadvantaged the residents of the Southwestern area is based on its rapid decline in population, approximately ten per cent over the 1950 decade, due largely to outmigration. Even with rising per capita income, the population decline implies that gross area income is probably falling. Consequently, the tax base available to finance the provision of local public goods is probably also declining. The relatively lower tax base is reflected in the lower expenditure per student on education in the Southwesternarea, approximately $\$ 300$ compared to approximately $\$ 350$ per student in the Northern Valley. This evidence is suggestive of the proposition that one of the major problems in declining areas is a relatively low investment in human capital by the residents of the localities.

The comparison however belies the proposition that the residents of rural areas are not responsive to economic opportunities. The rather dramatic population decreases of some of the Southwestern counties can certainly be interpreted in terms of migration to other areas in response to more attractive employment opportunities. Indeed, as shown in the paper by $\mathrm{Mr}$. Hirschberg, many residents of Appalachia commute long distances to employment centers outside the region. These two factors, residential migration and employment migration, have clearly been instrumental in keeping the growth of per capita income in the Southwestern Valley roughly equivalent to that of the Northern Valley.

The above comparison supports in a minor way, Hoover's contention that "access to markets has increased in importance for most industries relative to access to sources of raw materials and energy sources. "2 My first proposition that regional development policies are at best very costly and at worst doomed to failure is based largely on the importance of national markets for the firm's locational decision. Attempts to influence this decision either through direct subsidy or the provision of an attractive infrastructure will be very costly because of the difficulty of overcoming locational disadvantages. Indeed, the concept is similar to public utility regulation in its attempts to control firm behavior through governmental invervention. Continuing the IndustrialOrganization analogy, one might suggest that a firm's locational decision can be influencedmore efficiently by altering the economic structure or environment in which it operates. Decreasing transportation costs, perhaps through expanded highway programs, or moving the national market to the declining areas through significant new city programs would change the structure in favor of "remote" areas by improving access to national markets. However, this structural approach suffers from the basic problem that not all declining regions can be assisted. Improving access for all regions means that no region gains a significant locational advantage. And one regionmay be assisted only at the expense of other declining regions or of developed regions, a politically hazardous course.

Given the political context of Federal development policy it is hard to see how the "wish list" problem previously mentioned can be avoided. If the Congress sets up general rules concerning which areas are eligible for development funds, presumably any qualified area will be able to present a development program or "wish list" requesting federal funds. Any one area is motivated to do this because it receives all of the benefits of the funds and pays only a small part of the tax cost with the citizens of the rest of the country paying the remainder. But by Congressional definition the qualified area "needs" assistance. Arbitrary or political decisions about which needy areas will receive the assistance must then be made by the Executive branch, unless the budget is unlimited. 
In effect, this approach to regional development sets up what Buchanan and Tullock call a voting rule of one, concerning which they say: "Since each individual will be led to do this, and since individual benefits will exceedindividual costs over a wide extension of the activity, there will surely be an overinvestment... The decision making in which any individual may order collective action is useful as an extreme case in our analysis, but the model is not without some practical relevance for the real world. Specifically, such a rule is rarely encountered; but when legislative bodies, whatever the rules, respond to popular demands for public services on the basis solely of 'needs' criteria, the results may approximate those which would be attained under the extreme rule discussed here. ${ }^{3}$

An additional argument against Federal development programs, made by Henry Simons, is based on political as well as economic grounds. "In any case, modern democracy rests on free, responsible local government and will never be stronger than this foundation. Free, responsible local bodies correspond, in the politicalsystem, to free, responsible individuals or families and voluntary associations in the good society. A people wisely conserving its liberties will seek ever to enlarge the range and degree of localfreedom and responsibility. Insodoing, it may sacrifice possible proximate achievements. Doing specific good things by centralization will always be alluring. It may always seem easier to impose 'progress' on localities than to wait for them to effect it for themselves--provided one is not solicitous about the basis or sources of progress. A community imposing good local government from above may seem to get ahead rapidly for a time. Likewise, a community may temporarily raise its economic scale of life by living up its capital. And the analogy seems closely in point. Progress to which local freedom, responsibility, and experimentation have pointed the way may be accelerated for a time and effected more uniformly by the short cut of central action. But such short-cutting tends to impair or to use up the roots of progress in order to obtain briefly luxuriant bloom. "4

Briefly, any attempt to alter the market distributions of population or per capita incomes will be very costly simply in terms of the subsidies which must be offered. These costs are increased by the constraints imposed by the political framework in which the subsidies must be made. Finally, Simons and others have suggested that progress imposed on localities by the Federal Government is dangerous to our political system.

However, Mr. Rothblatt's paper, to which these comments a re directed, is more concerned with the planning functions of the Appalachian Regional Commission (ARC) than with its economic or political rationale. He argues convincingly that the ARC, which was initiated to a large extent by the state governments, has been a more effective planning agency in terms of local and state acceptance than have other Federal attempts at planning. In fact, Mr. Rothblatt's discussion of the ARC as a planning institution plus his emphasis on block grants or modified block grants indicates that the ARC at least to some extent meets Simons' concept of the proper role of larger governmental units. "Larger units may properly do all manner of things to facilitate local discharge of service responsibilities. They may conduct research, formulate standards, publicize relevant information, offer training for local personnel, and even contribute funds, provided that assistance is not (long? ) combined with positive, direct control and that local responsibility remains essentially unimpaired. This means, in terms of one obtrusive issue, that all grants of funds from above should be (tend to become) bloc grants and largely unconditional. Grants should involve a minimum of central control and should not (permanently) be made for special purposes. Moreover, all Federal grants should be made to and through the states, even when intended for local bodies--and, again, unconditionally. $" 5$ 
However, one fundamental question remains unanswered. "Would the planning processes of the Appalachian states have developed in the absence of ARC." The benefits which Rothblatt claims for the ARC planning processes, namely the setting of time priorities for projects, the coordination of the completion of public projects and the relationship between expenditures for projects and public revenues, depend crucially upon the answer to this question. If the very basic planning necessary for the achievement of these benefits would have been undertaken anyway, they cannot be counted as part of the benefits of the ARC. I remain skeptical of the position that without the ARC this planning would not have occurred. After all, many states do not have the Federal inducement for this type of planning or what is, in effect, good state government. Nevertheless, they spend their public revenues in a reasonably effective way.

In short, the papers presented have not convinced me that regional programs based on the promotion of state and local planning and on various subsidy schemes areworth the price that we must pay for them. Convincing arguments for regional development programs could possibly be made on the basis of spillovers or externalities from one area to another. Or perhaps they could be made on national or civil defense grounds. However, at this point I do not understand why declining regions should not be allowed to decline.

One basic problem with this approach, as suggested in the comparison above, is that individuals in declining areas must pay a relatively high tax price for public services. Individuals, not areas, are trapped in a vicious circle. Outmigration in response to better opportunities els ewhere implies that the individuals remaining in the region will not have equal opportunities to develop their individual capacities. So, over time, the individuals remaining in the declining areas are unable to take advantage of the economic opportunities available to them elsewhere. Consequently, subsidized public works projects which assist individuals in terms of development of human capital, namely health and education (including vocational education) programs, are desirable on the grounds of equality of opportunity. The argument implies however that the public works programs should be spatially dispersed since their major effect is on human welfare not regional welfare. Nothing in the argument as stated suggests that these programs should or need be Federal programs. However, the incorporation of spillover effects, e.g., the difficulties caused for large cities by uneducated rural migrants, may suggest that Federal programs are preferable 


\section{FOOTNOTES}

*As a last minute discussant, I was unable to see Mr. Rothblatt's paper in time to make detailed comments on it. Consequently, a large proportion of this paper is devoted to a general analysis of regional development programs. I wish to thank Mr. James Ruffner, a student at the University of Virginia, for collecting the data and providing the calculations underlying Table I. Mr. Ruffner's task was complicated by the severe time constraint under which we worked.

${ }^{1}$ I define the Northern Shenandoah Valley to include the counties of Augusta, Frederick, Page, Rockingham, Shenandoah, and Warren. The Southwestern area includes the counties of Buchanan, Dickinson, Lee, Russell, Scott, Smyth, Tazewell, Washington, and Wise.

${ }^{2}$ Edgar M. Hoover, "Some Old and New Issues in Regional Development, "Regional Economic Development in the United States, (U.S. Department of Commerce, Economic Development Administration, 1967), IV, p. 23.

${ }^{3}$ James M. Buchanan and Gordon Tullock, The Calculus of Consent, (The University of Michigan Press, 1962), pp. 66-67.

${ }^{4}$ Henry C. Simons, "Introduction: A Political Credo," Economic Policy for a Free Society, (The University of Chicago Press, 1948), p. 13. 5

Ibid., p. 17. 